\title{
Epidemias de ferrugem asiática no Rio Grande do Sul explicadas pelo fenômeno ENOS e pela incidência da doença na entressafra
}

\author{
Claudinei Antonio Minchio, Marcelo Giovanetti Canteri, Lucas Henrique Fantin e Marcelo Augusto de Aguiar e Silva
}

Universidade Estadual de Londrina, Centro de Ciências Agrárias, Departamento de Agronomia, Rod. Celso Garcia Cid, PR 445, Km 380, Cx. Postal 6001, 86051-990, Londrina, PR.

Autor para Correspondência: Marcelo Giovanetti Canteri (canteri@uel.br)

Data de chegada: 12/07/2016. Aceito para publicação em: 29/07/2016.

$10.1590 / 0100-5405 / 2219$

\section{RESUMO}

Minchio, C.A.; Canteri, M.G.; Fantin, L.H. Epidemias de ferrugem asiática no Rio Grande do Sul explicadas pelo fenômeno ENOS e pela incidência da doença na entressafra. Summa Phytopathologica, v.42, n.4, p.321-326, 2016.

Estudou-se a interferência da variabilidade da variabilidade climática e do número de relatos de ferrugem asiática na entressafra sobre a epidemia da doença no estado do Rio Grande do Sul, durante 11 safras agrícolas. A ocorrência da doença foi obtida a partir de relatos apresentados no Consórcio Antiferrugem e dividida entre os períodos "Safra", "Entressafra" e "Ano Todo". Os dados das epidemias foram testados para correlação, via regressões polinomiais lineares e quadráticas, com as variáveis climáticas: precipitação pluvial, índice padronizado de precipitação - SPI, índice de oscilação sul - IOS e anomalia da Temperatura na Superfície do Mar - SST no Oceano Pacífico Tropical e número de ocorrências da doença no período de entressafra. Os índices que melhor explicaram a variação das ocorrências da doença para o período "Ano Todo" foram o SST e IOS, com coeficientes de determinação $\left(\mathrm{R}^{2}\right)$ de 0,94 e 0,59 , respectivamente. As ocorrências de ferrugem no período "Entressafra" influenciaram positivamente nas ocorrências no período "Safra".

Palavras-chave: Inóculo inicial, Phakopsora pachyrhizi, epidemiologia, modelo de previsão

\section{ABSTRACT}

Minchio, C.A.; Canteri, M.G.; Fantin, L.H. Soybean rust epidemics in Rio Grande do Sul explained by ENSO phenomenon and off-season disease incidence. Summa Phytopathologica, v.42, n.4, p.321-326, 2016.

The interference of climatic variability and number of Asian rust reports in the off-season on the epidemics of the disease was studied in the state of Rio Grande do Sul for 11 seasons. The disease occurrence was obtained from reports presented at Antirust Consortium and divided among the periods "season", "off-season" and "whole year". Data on the epidemics were tested for correlation, via linear and quadratic polynomial regression, with climate variables: rainfall, standardized precipitation index - SPI, Southern Oscillation Index - SOI and sea surface temperature anomaly - SST in the Tropical Pacific Ocean, and number of occurrences of the disease in the off-season. The indices that best explained the variation in disease occurrence for the period "whole year" were SST and SOI, and coefficients of determination $\left(\mathrm{R}^{2}\right)$ were 0.94 and 0.59 , respectively. Rust occurrences in the period "off-season" positively influenced the occurrence in the "season" period.

Keywords: Initial inoculum, Phakopsora pachyrhizi, epidemiology, predict models

O Estado do Rio Grande do Sul se destaca como o terceiro maior produtor de soja do Brasil, alcançando produção superior a 16 milhões de toneladas na safra 2015/2016 (3). Doenças como a ferrugem asiática da soja, causada por Phakopsora pachyrhizi Syd. \& P. Syd. estão entre os fatores que afetam negativamente a produtividade. Yorinori et al. (16) estimaram potencial destrutivo na ordem de 10 a $90 \%$.

A severidade e intensidade da epidemia estão correlacionadas com a ocorrência das primeiras precipitações $(1,7,12)$, e quantidade de inóculo inicial $(6,7,13)$. Entre os fatores que afetam a ocorrência de chuvas está o fenômeno El Niño Oscilação Sul (ENOS), resultado da interação oceano-atmosfera, levando a anomalias climáticas que afetam o clima em diversas partes do mundo (14).

Vários índices têm sido utilizados para medir a intensidade do ENOS, dentre eles o índice de oscilação sul - IOS, que reflete a diferença de pressão atmosférica entre Taiti $\left(17,5^{\circ} \mathrm{S}-149,6^{\circ} \mathrm{W}\right)$ e Darwin $\left(12,4^{\circ}\right.$ $\left.\mathrm{S}-130,9^{\circ} \mathrm{E}\right)$, localizado na Austrália. O IOS mede a intensidade da Oscilação Sul (componente atmosférico), na região Niño 3 e a anomalia da Temperatura na Superfície do Mar - SST mede a intensidade do El Niño (componente oceânica).
O índice padronizado de precipitação (SPI) desenvolvido por McKee et al. (11) é utilizado como um quantificador de seca meteorológica capaz de monitorá-la em diversas escalas de tempo, reconhecendo diferentes tipos de seca em sua análise. Obtido apenas de dados de precipitação pluvial, é adotado em diversas partes do mundo, em programas e ações governamentais que visam realizar a análise de riscos e implantação medidas que diminuam o impacto socioeconômico causado pela seca (15).

Informações sobre a ocorrência da ferrugem asiática da soja em todo o território brasileiro são disponibilizadas através de uma plataforma em website denominada Consórcio Antiferrugem, organizada pela EMBRAPA/Soja em parceria com diversas instituições (4). Megeto et al. (12) utilizaram os dados do Consórcio Antiferrugem na avaliação da influência dos elementos meteorológicos sobre as ocorrências de ferrugem asiática de soja, através da indução de árvores de decisão e confirmaram a ação positiva da precipitação pluvial.

O estudo teve por objetivo avaliar a relação de ocorrência de ferrugem asiática da soja no período de entressafra com a precipitação pluvial, SPI, IOS e SST, para explicar as ocorrências no período "Safra" no Rio Grande do Sul. 


\section{MATERIAL E MÉTODOS}

O fenômeno ENOS é definido a partir dos índices IOS e SST que são disponibilizados pela National Oceanic and Atmospheric Administration-NOAA (http://www.cpc.ncep.noaa.gov/data/indices/). Para a obtenção destes índices considerou-se a região sobre o Oceano Pacífico Tropical, definida como Niño 3.4, compreendida entre as latitudes de $5^{\circ} \mathrm{N}$ a $5^{\circ} \mathrm{S}$ e longitudes de $170^{\circ} \mathrm{W}$ a $120^{\circ} \mathrm{W}$, disponíveis trimestralmente no site do NOAA (9).

Para a obtenção do SPI e da precipitação pluvial nas Regiões do Estado do Rio Grande do Sul, foram utilizados os dados disponibilizados pelo CPTEC/INPE - Centro de Previsão do Tempo e Estudos Climáticos/ Instituto Nacional de Pesquisas Espaciais (www. cptec.inpe.br/clima) entre 2004 e 2015, que corresponde ao período de relatos de ferrugem do Consórcio Antiferrugem.

O valor SPI é calculado a partir de janeiro de 1981 até presente data, para diversas escalas temporais. Neste trabalho foi utilizado dados trimestrais (SPI-3). Nesta estimativa, o Brasil é dividido em 124 regiões, com dimensão de $2,5^{\circ}$ x $2,5^{\circ}$ (latitude x longitude). O estado do Rio Grande do Sul é dividido nas regiões 115, 118, 119, 120, 123 e 124 definidas pelo INPE (5).

As informações de ocorrência da ferrugem asiática da soja foram obtidas a partir de dados do Consórcio Antiferrugem ( $<$ http//www. consorcioantiferrugem.net $>$ ) que disponibiliza relatos de identificação da doença em cada município, inseridas por pesquisadores e laboratórios credenciados na rede. As ocorrências foram sistematizadas e agrupadas por trimestre em escala móvel, conforme Tabela 1.

Foram utilizados dados de ocorrência no intervalo entre as safras de 2004 a 2015 e organizados de acordo com a região definida pelo INPE; safra; trimestre; ocorrência acumulada no trimestre; precipitação pluvial; SPI; IOS e SST,

As relações entre o número de ocorrências acumuladas nos períodos de "Ano Todo", "Safra" e "Entressafra", com os índices citados (precipitação pluvial, SPI, IOS e SST) foram analisadas por regressão polinomial linear (10) e polinomial quadrática por trimestre descrito na Tabela 1.
Tabela 1. Períodos de safra e entressafra com a distribuição dos meses nos trimestres considerados.

\begin{tabular}{ccccc}
\hline Período & Trimestre & \multicolumn{3}{c}{ Mês } \\
\hline Safra & ASO & Agosto & Setembro & Outubro \\
Safra & SON & Setembro & Outubro & Novembro \\
Safra & OND & Outubro & Novembro & Dezembro \\
Safra & NDJ & Novembro & Dezembro & Janeiro \\
Safra & DJF & Dezembro & Janeiro & Fevereiro \\
Safra & JFM & Janeiro & Fevereiro & Março \\
Safra & FMA & Fevereiro & Março & Abril \\
Entressafra & MAM & Março & Abril & Maio \\
Entressafra & AMJ & Abril & Maio & Junho \\
Entressafra & MJJ & Maio & Junho & Julho \\
Entressafra & JJA & Junho & Julho & Agosto \\
Entressafra & JAS & Julho & Agosto & Setembro \\
\hline
\end{tabular}

A variável resposta foi definida como o número de ocorrências no "Ano Todo", na "Safra" e na "Entressafra", estratificadas pelos atributos de região, ano da safra e trimestre. Foram obtidos os coeficientes de determinação $\left(\mathrm{R}^{2}\right)$ e respectivo p-valor, que corresponde ao risco de se rejeitar a hipótese de nulidade sendo esta verdadeira. Também foi analisada a relação entre as ocorrências de ferrugem na "Entressafa" com a "Safra", pela analise de regressão, obtendo-se os coeficientes de determinação $\left(\mathrm{R}^{2}\right)$ e p-valor.

\section{RESULTADOS E DISCUSSÃO}

Os resultados obtidos na Tabela 2, indicaram que o SST, precipitação pluvial acumulada e SPI, foram os que melhor explicaram as ocorrências de ferrugem asiática da soja, tanto para período "Ano Todo" como para "Safra", não se aplicando para o período "Entressafra". O SST foi o índice que apresentou os maiores coeficientes de determinação para

Tabela 2. Coeficiente de determinação $\left(\mathrm{R}^{2}\right)$ das regressões lineares entre a ocorrência de ferrugem asiática no ano todo, na safra e na entressafra, estratificados por regiões, safras (ano) e trimestres, com os índices: precipitação acumulada, SPI, IOS e SST, agrupados por ano todo, safra e entressafra, no Rio Grande do Sul.

Coeficiente de determinação das ocorrências

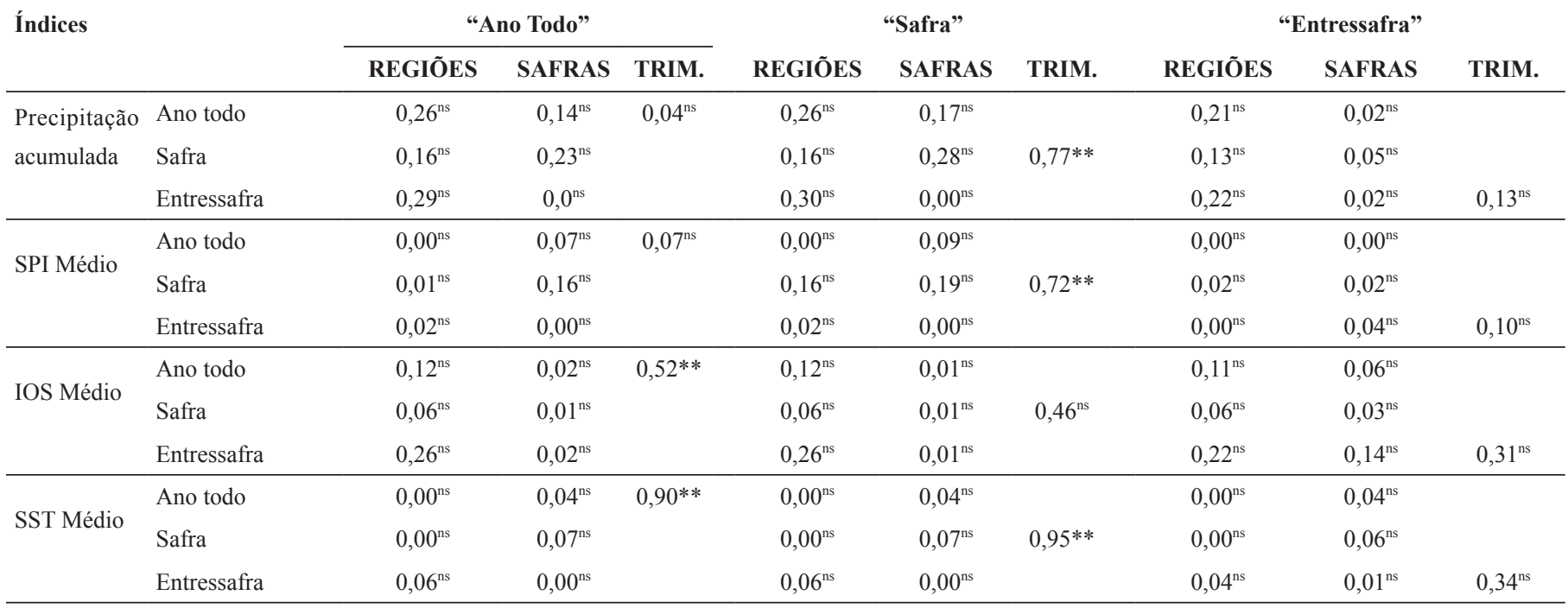

(ns) não significativo; $(*)$ significativo a $5 \% ;(* *)$ significativo a $1 \%$ 
as condições do estado do Rio Grande do Sul.

No extremo sul do Brasil, quando as anomalias de SST e SPI são positivas, há um aumento de precipitação pluvial acima da normal climatológica caracterizando a fase El Niño. O fenomeno inverso é denominado La Niña. Enquanto o El Niño ocasiona chuvas em grandes proporções, na região sul, na região norte/nordeste, provoca um período seco.

O Estado do Rio Grande do Sul situa-se no extremo sul brasileiro e os efeitos dos fenômenos El Niño como La Niña estão evidenciados neste estado, demonstrado pela relação existente entre os índices SST, precipitação pluvial e SPI (Tabela 2).

A Figura 1 mostra a regressão polinomial quadrática entre as ocorrências e precipitação pluvial para o período "Safra", com $\mathrm{R}^{2}$ de 0,77 e $1 \%$ de nível de significância.

A regressão polinomial quadrática entre dados de SPI dos trimestres, dentro do período "Safra”, apresentou o $\mathrm{R}^{2}$ de 0,81 (Figura 2), com nível de significância menor que $1 \%$, com melhor ajuste do que a regressão linear com $\mathrm{R}^{2}$ de 0,72 (Tabela 2).

$\mathrm{Na}$ Figura 3A, a regressão polinomial quadrática entre as ocorrências e SST para o período “Ano Todo", apresentou $\mathrm{R}^{2}$ de 0,94 , e $1 \%$ de nível de significância, Com melhor ajuste que a regressão linear, cujo $\mathrm{R}^{2}$ foi de 0,90 .

$\mathrm{Na}$ regressão polinomial quadrática com o SST dos trimestres dentro do período "Safra" registrou o $\mathrm{R}^{2}$ igual ao da regressão linear, no valor de 0,95 e nível de significância de 1\% (Figura 3B).

Os resultados confirmaram a importância da precipitação pluvial e sua relação com a ocorrência de ferrugem asiática da soja $(1,7,8,12)$. Os índices que melhor explicaram a variação interanual da ocorrência da doença no Rio Grande do Sul foram o SST, a precipitação pluvial e o SPI.

Entretanto ainda observou-se que as relações entre a ocorrência e estes índices foram inversamente proporcionais em todos os casos, indicando que provavelmente exista outro fator interferindo nesta relação. Por exemplo, a baixa temperatura do ar no inverno,

Período: SAFRA

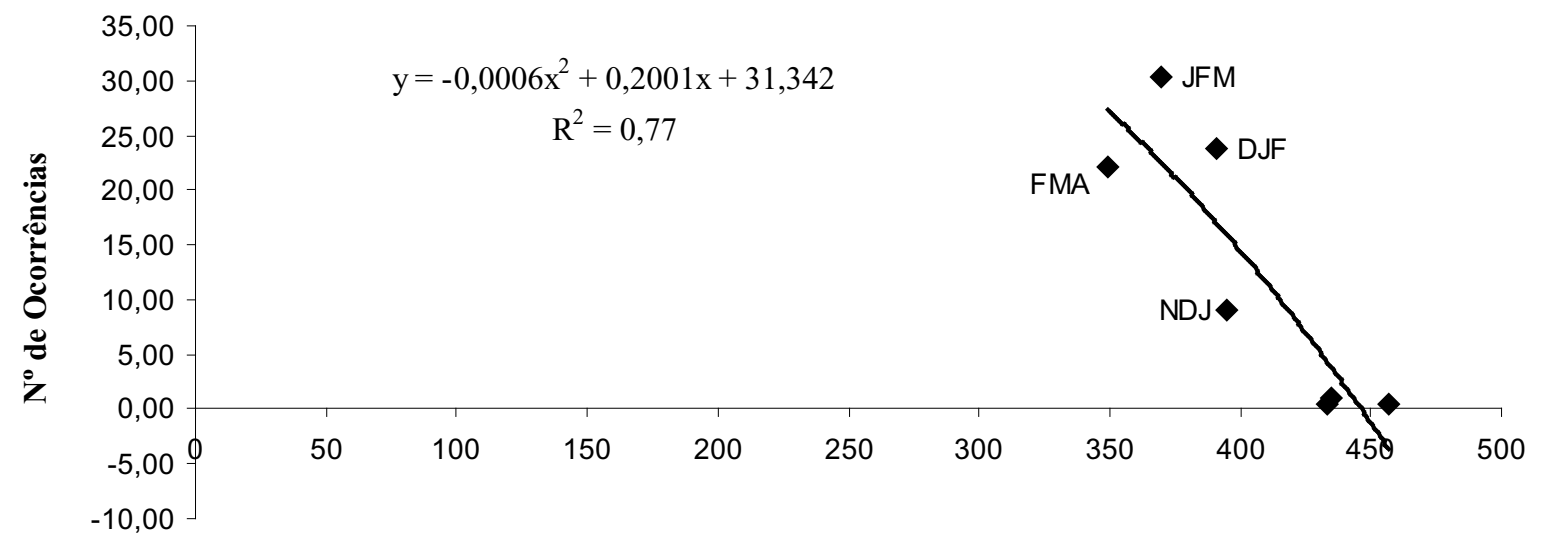

Precipitação Pluviométrica (mm)

Figura 1. Regressão polinomial quadrática entre as ocorrências (eixo Y) e precipitação acumulada na safra (eixo X), na escala temporal trimestral, para todas as regiões e anos agrícolas do Rio Grande do Sul.

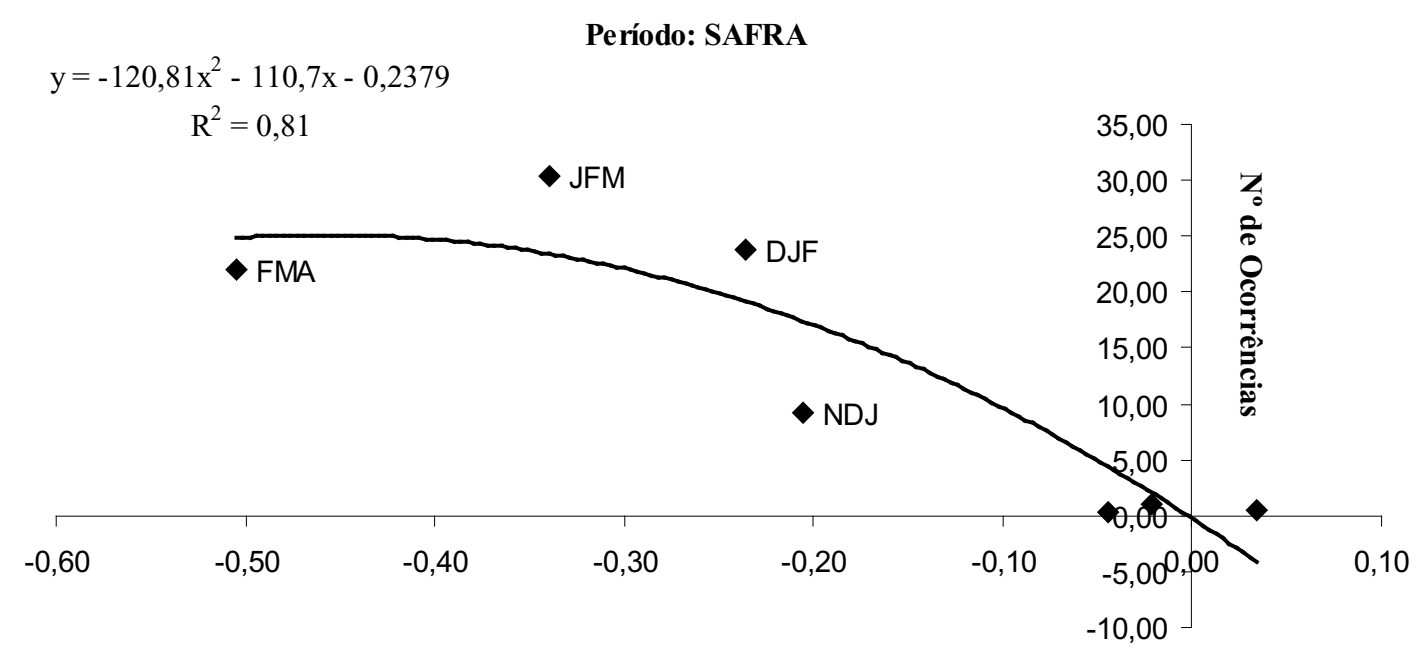

SPI-3

Figura 2. Regressão polinomial quadrática entre as ocorrências (eixo Y) e SPI (eixo X), na escala temporal trimestral, na "Safra", para todas as regiões e anos agrícolas do Rio Grande do Sul. 


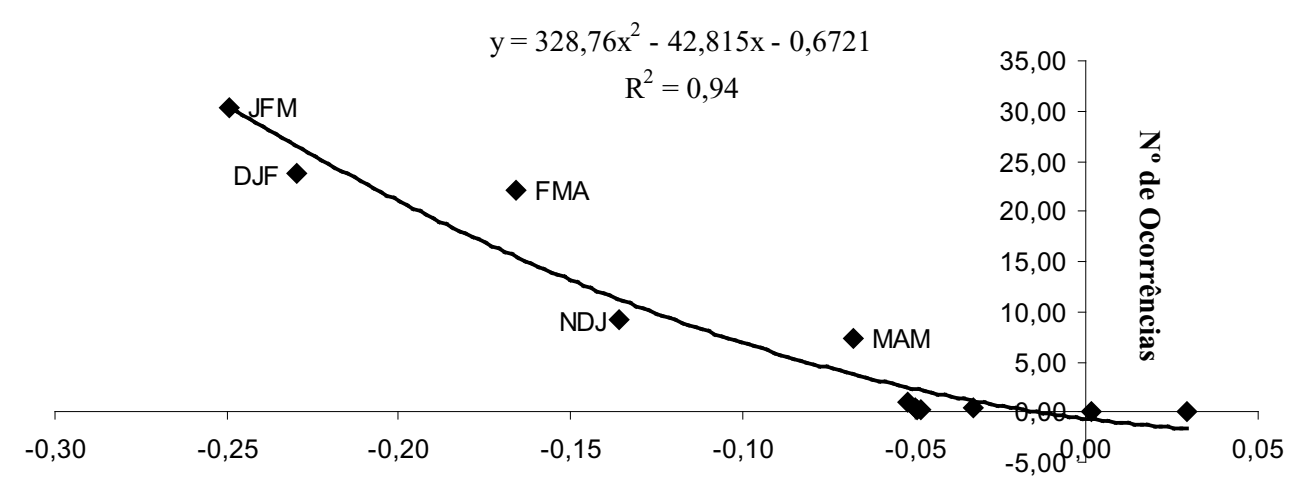

SST Niño 3.4

B

\section{Período: SAFRA}

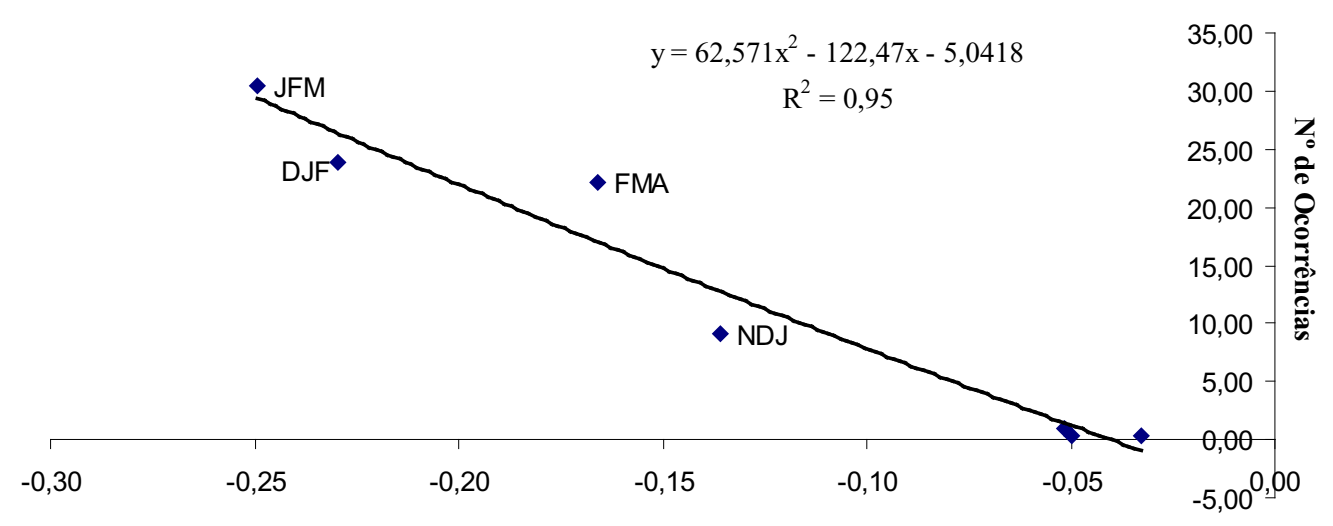

SST Niño 3.4

Figura 3. Regressão polinomial quadrática entre as ocorrências (eixo Y) e SST (eixo X), na escala temporal trimestral, no período "Ano Todo" (A) e período "Safra" (B), para todas as regiões e anos agrícolas do Rio Grande do Sul.

característica no estado, é um fator limitante para a que ocorra a sobrevivência do patógeno em plantas guaxas e o início da semeadura da soja no estado.

De modo anormal, nos anos agrícolas com temperaturas de inverno elevadas, é possível esperar aumento da ocorrência de ferrugem no período de safra, pois se associadas a chuvas abundantes, propiciam a sobrevivência de plantas guaxas e condições de plantio antecipado promovendo o desenvolvimento de epidemias severas e precoces.

Blain (2) propõe uma adaptação do SPI para os interesses da agrometeorologia, além disso, os resultados indicaram a possibilidade da utilização deste índice para os interesses da fitopatologia, e da mesma forma o índice SST.

Além da análise da variabilidade interanual das ocorrências da doença, destacou- se ainda a variabilidade intra-anual. Foi possível estabelecer relações entre as ocorrências no período "Entressafra" e seu efeito nas ocorrências no período "Safra" e "Ano Todo" dentro do mesmo ano agrícola, conforme observado na Tabela 3.

Verificou-se que para todos os anos agrícolas, o número de ocorrências no período "Entressafra" influenciou positivamente as ocorrências do período "Safra" e do "Ano Todo", com o coeficiente
Tabela 3. Ocorrências da doença no período "Entressafra", "Safra" e "Ano Todo" nos anos agrícolas no Rio Grande do Sul e a coefíciente de determinação da regressão da "Entressafra" com "Safra" e "Ano Todo".

\begin{tabular}{lccc}
\hline \multirow{2}{*}{ SAFRA } & \multicolumn{3}{c}{ OCORRÊNCIA (média trimestral) } \\
\cline { 2 - 4 } & ENTRESSAFRA & SAFRA & ANO TODO \\
\hline $2004 / 2005$ & 0,27 & 2,81 & 1,75 \\
$2005 / 2006$ & 3,44 & 22,14 & 14,35 \\
$2006 / 2007$ & 8,90 & 37,25 & 25,44 \\
$2007 / 2008$ & 0,93 & 9,12 & 5,71 \\
$2008 / 2009$ & 3,07 & 15,17 & 10,13 \\
$2009 / 2010$ & 0,47 & 17,17 & 10,21 \\
$2010 / 2011$ & 0,23 & 12,69 & 7,50 \\
$2011 / 2012$ & 0,20 & 1,07 & 0,71 \\
$2012 / 2013$ & 0,33 & 7,90 & 4,75 \\
$2013 / 2014$ & 0,33 & 10,33 & 6,17 \\
$2014 / 2015$ & 1,20 & 7,27 & 4,68 \\
\hline Média & 1,76 & 12,99 & 8,31 \\
\hline R2 & \multicolumn{4}{c}{$0,85^{* *}$} \\
\hline (**)significativo a 1 \% & & $0,80^{* *}$ &
\end{tabular}

(**)significativo a $1 \%$ 


\section{SAFRAS: Entressafra X Ano Todo}

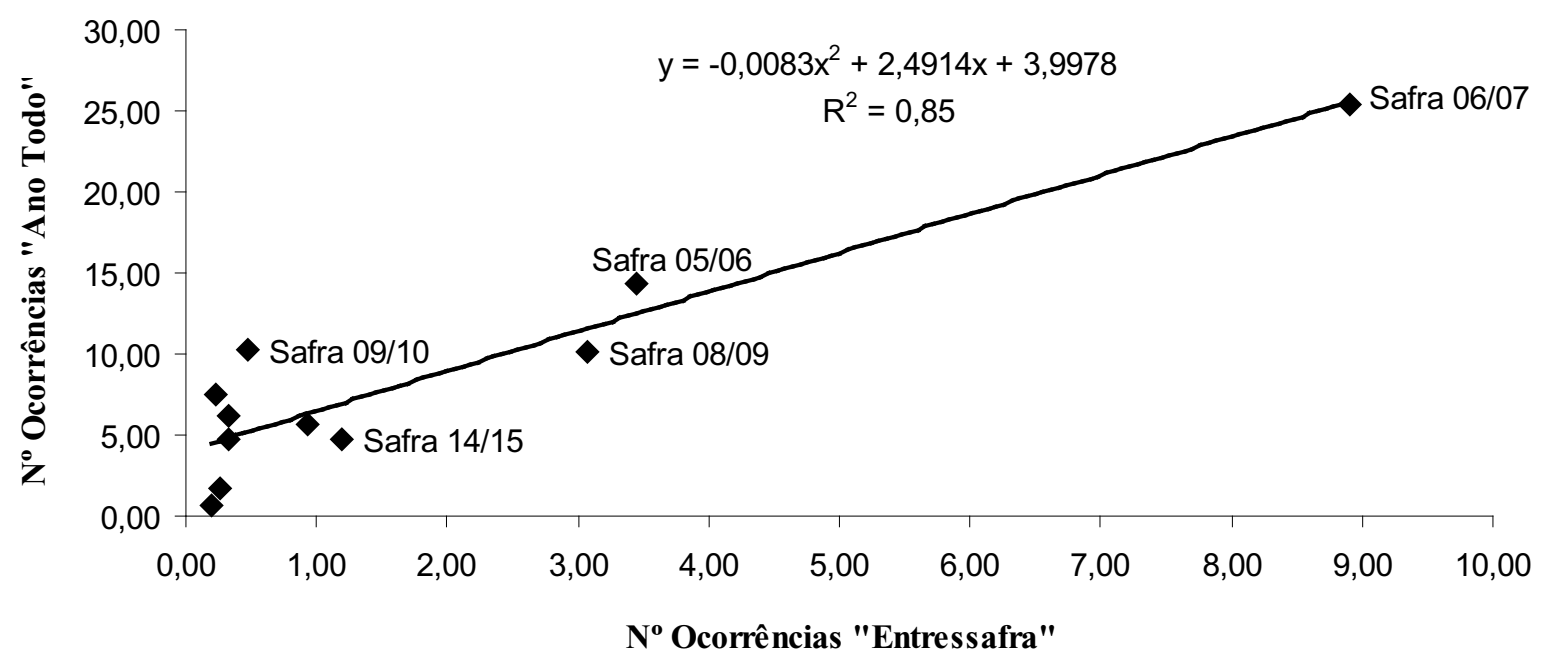

SAFRAS: Entressafra X Safra

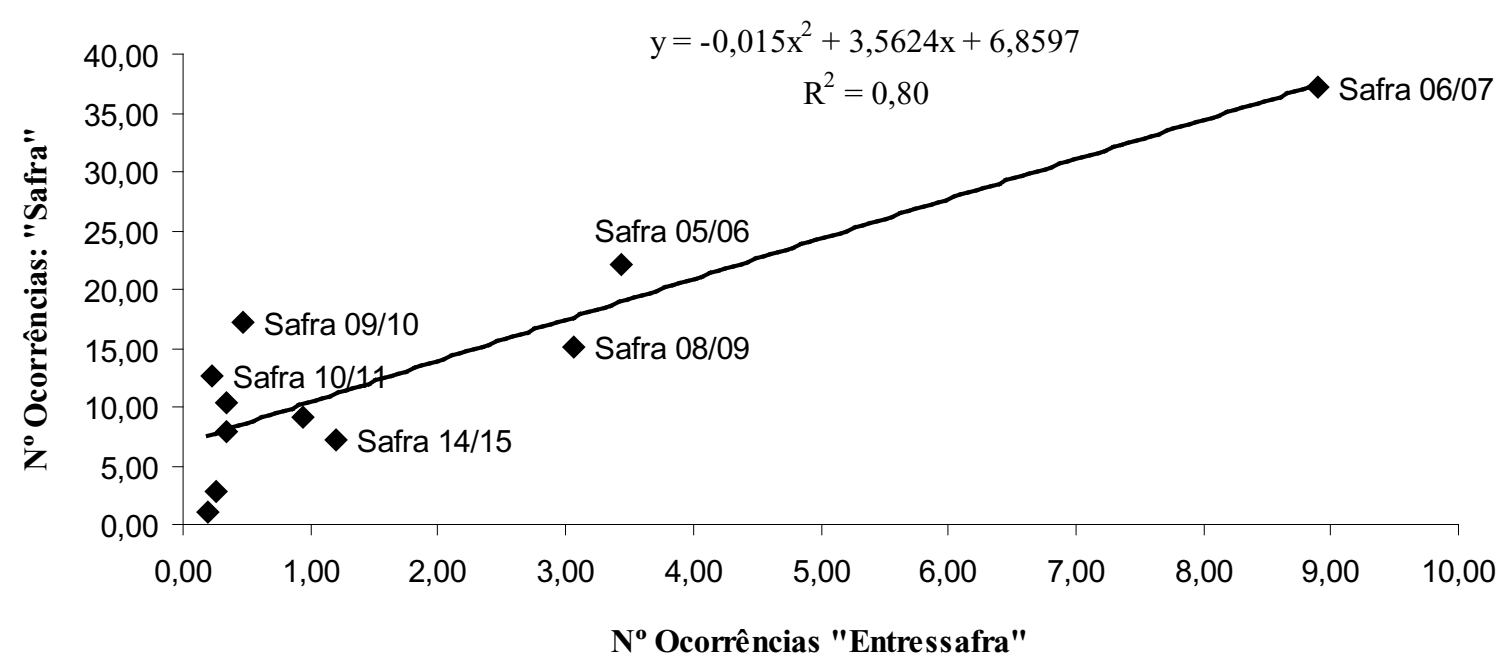

Figura 4. Regressão quadrática entre as ocorrências da doença no período "Entressafra" com os períodos "Ano Todo" (A) e "Safra" (B), dentro de cada ano agrícola do Rio Grande do Sul

de determinação $\left(\mathrm{R}^{2}\right)$ da regressão polinomial quadrática de 0,80 e 0,85 , respectivamente, significativos a $1 \%$ (Tabela 3 ).

O resultado ressalta a importância da implantação do vazio sanitário também para o Rio Grande do Sul, visto que, assim como o estado de Santa Catarina, não possui leis que determinam o estabelecimento deste período. Na região sul, somente o estado do Paraná possui legislação a respeito.

Foi verificada a influência da chuva sobre a epidemia. Assim como, o inóculo inicial, inferenciado pelas ocorrências no período "Entressafra", pode também explicar as ocorrências do período "Safra" e "Ano Todo", confirmando os resultados de Canteri et al. (6), Del Ponte (7) e Minchio (13). Portanto as ocorrências do Consórcio Antiferrugem no período "Entressafra" influenciariam o número de ocorrências durante a safra vindoura, numa relação conforme mostra a Figura 4.

Para as condições do estado do Rio Grande do Sul, a ocorrência de ferrugem asiática do período "Safra" e no período "Ano Todo", têm relação, inversamente proporcional, com a anomalia da temperatura na superfície do mar (SST), do Oceano Pacífico tropical, o Índice Padronizado de Precipitação (SPI) e a precipitação pluvial acumulada independente do trimestre ou ano, nas regiões e safras analisadas.

As ocorrências de ferrugem no período "Entressafra" influenciaram positivamente nas ocorrências tanto do período "Safra", como "Ano Todo", para as regiões e anos agrícolas estudados.

Justifica-se portanto a indicação da implantação no Rio Grande do Sul de legislação para a adoção do período de vazio sanitário. 


\section{REFERÊNCIAS}

1. Bergamin Filho, A. Epidemiologia comparativa: ferrugem da soja e outras doenças. In: Zambolin, L. (Org.). Ferrugem asiática da soja. Visconde do Rio Branco: Suprema Gráfica e Editora, 2006. p.15-35.

2. Blain, G.C. Aplicação do conceito do índice padronizado de precipitação à serie decendial da diferença entre precipitação pluvial e evapotranspiração potencial. Bragantia, Campinas, v.70, n.1, p.234-245, 2011.

3. Brasil. Companhia Nacional de Abastecimento. Acomp. safra bras. grãos, v. 9 Safra 2015/16 - Nono levantamento, Brasília, p. 123-132, junho 2016. Disponível em < http://www.conab.gov.br/OlalaCMS/uploads/ arquivos/16 $06 \quad 09 \quad 16 \quad 49 \quad 15$ boletim graos junho 2016 - final. pdf $>$ Acesso em: 10 de agosto de 2016.

4. Brasil; Consórcio Antiferrugem. Consórcio antiferrugem. Disponível em: < http://www.consorcioantiferrugem.net/portal/ >. Acesso em: 10 ago. 2015.

5. Brasil. Instituto Nacional de Pesquisas Espaciais. Informações sobre produtos de monitoramento climático mensal e sazonal das chuvas no Brasil na página do CPTEC/INPE. Cachoeira Paulista: CPTEC/ INPE, 2014. Disponível em: < http://clima1.cptec.inpe.br/ rclima1/pdf/ Documento produto indice.pdf>. Acesso: em 08 ago. 2015.

6. Canteri, M.G.; Tsukahara, R.Y.; Silva, O.C. Monitoramento das variáveis ambientais para controle da ferrugem asiática da soja. In: XL Congresso Brasileiro de Fitopatologia, 2007, Maringá. Fitopatologia Brasileira. Brasilia : SBF, 2007. v. 32. p. 65-66.

7. Del Ponte, E.M.; Godoy, C.V.; Li, X.; Yang, X.B. Predicting severity of asian soybean rust epidemics with empirical rainfall models. Phytopathology, St. Paul, v.96, n.7, p.797-803, 2006.

8. Del Ponte, E.M. Retrospectiva e tendências em modelagem matemática e previsão de ferrugem asiática. Revista Plantio Direto, Passo Fundo, v.96, n.1, p.21-30, 2006.
9. Estados Unidos da América. National Oceanic Atmospheric Administration. El niño- Southern oscilation- Current status. 2015. Disponível em: < http://www.cpc.ncep.noaa.gov/products/precip/CWlink/MJO/enso.shtml >. Acesso em: 10 ago. 2016.

10. Ferreira, D.B. Relações entre a variabilidade da precipitação e a produtividade agrícola de soja e milho nas regiões sul e sudeste do Brasil. 2005. 123 páginas. Dissertação (Mestrado em Meteorologia) Instituto Nacional de Pesquisas Espaciais, São José dos Campos.

11. McKee, T.B.; Doesken, N.; Kleist, J. The relationship of drought frequency and duration to time scales. In: Conference on Applied Cimatology, 8., 1993, Anaheim. Disponível em: < http://ccc.atmos.colostate.edu/ relationshipofdroughtfrequency.pdf >. Acesso: em 10 ago. 2016.

12. Megeto, G.A.S.; Oliveira, S.R.M.; Del Ponte, E.M.; Meira, C.A.A. Árvore de decisão par classificação de ocorrências de ferrugem asiática em lavouras comerciais com base em variáveis meteorológicas. Engenharia Agrícola, Jaboticabal, v.34, n.3, p.590-599, 2014.

13. Minchio, C.A. Determinação da provável origem do inóculo de Phakopsora pachyrhizi e interação entre estádio fenológico, favorabilidade ambiental e presença do inóculo para controle da doença. 2011. 116f. Dissertação (Mestrado em Agronomia) - Universidade Estadual de Londrina, Londrina.

14. Ropelewski, C.F.; Halpert, M.S. Global and regional scale precipitation patterns associated with the El Niño / Southren Oscillation. Monthly Weather Review, New York, v.115, p.1606-1626, 1987.

15. Teixeira, C.F.A.; Damé, R.C.F.; Bacelar, L.C.S.; Silva, G.M.; Couto, R.S. Intensidade da seca utilizando índices de precipitação. Revista Ambinte \& Água: An Interdisciplinary Journal of Applied Science, Taubaté, v.8, n.3, p.203-2013, 2013.

16. Yorinori, J.T.; Paiva, W.M.; Frederick, R.D.; Costamilan, L.M.; Bertagnolli, P.F. Epidemics of soybean rust (Phakopsora pachyrhizi) in Brazil and Paraguay from 2001 to 2003. Plant Disease, St. Paul, v.89, n.6, p.675-677, 2005. 